\title{
Safety and reliability in biogas plants
}

\author{
V. Torretta ${ }^{1}$, S. Copelli ${ }^{2}$, S. Contini ${ }^{1} \&$ E. C. Rada ${ }^{3}$ \\ ${ }^{I}$ Department of Biotechnologies and Life Sciences, \\ Insubria University, Italy \\ ${ }^{2}$ Department of Science and High Technology, Insubria University, Italy \\ ${ }^{3}$ Department of Civil, Environmental and Mechanical Engineering, \\ University of Trento, Italy
}

\begin{abstract}
In the last ten years, everyone has been talking about biogas plants: politicians, ecologists, technicians, economists, laymen and experts. In other words: biogas has become fashionable. The energy crisis of the next few years shall be the shortage of fuel for the daily needs of millions of people and biogas plants seem to be a promising solution to help in solving this problem. Biogas plants are complicated enough to require both a total involvement with their specific technology and an accurate risk assessment for design purposes. With particular reference to this last feature, the number of accidents involving biogas plants has been too many to ignore. Frequent accident causes are: leakage in the storage tank and/or in the biogas distribution network, formation of flammable mixtures during maintenance operations, accidental release of $\mathrm{H}_{2} \mathrm{~S}$, effluent discharge and developing of high pressure inside the digester. Biogas plants are often operated wrongly, deficient in technological details and incorrectly scaled-up. Moreover, all these mistakes are repeated over and over again. Therefore, there is the pressing need for a quick procedure to assess the reliability of these plants in order to operate them safely. In this work, a simple but accurate risk assessment has been carried out on a case study biogas plant using a fault tree analysis applied to the top event "fire in the digester" (one of the main causes of accident in this plant's typology). Results have shown that the overall risk (considering one year of mission time) is less than $10^{-8}$. This value is acceptable considering that, near these plants, the number of inhabitants does not exceed 100 persons. Keywords: biogas plants, risk assessment, unconfined explosions, fires, safety.
\end{abstract}




\section{Introduction}

Biogas is produced from a wide variety of waste in anaerobic digesters [1-4]. Anaerobic digestion is a process which transforms organic matter into gases such as methane and carbon dioxide. There are several processes for the production of biogas, depending on the type of organic waste used [5, 6]. In fact, biogas can come from several different types of raw materials: sewage sludge, food waste, manure (from cows, pigs etc.), residues from agriculture, distillery by-products and organic fraction of municipal solid wastes [7-10].

Both the total amount and the quality of the produced biogas depend on the sort of used raw materials [11]. Moreover, the involvement of different raw materials requires different processes, which unavoidably mean different sorts of upgrading or removing techniques. Therefore, it appears very difficult to fix a global yield in order to study all uses of biogas or to clearly identify hazards and risks in a biogas plant.

Despite all these criticalities, biogas is a fast-developing energy resource in Europe because it represents a valorisation of wastes and can be easily produced all over the world for a great variety of applications: transport, stationary energy use, heat and combustion. In 2010, European primary energy production from biogas benefited an annual growth of $31.3 \%$ up to reach a production of $20.9 \cdot 10^{9} \mathrm{~kg}[12]$.

The main emerging risks related to the quick development of biogas, which is flammable, toxic, and possibly pathogen (microbiological hazard), are: 1) leakage in the storage tank and/or in the biogas distribution network, 2) formation of flammable mixtures during the digester maintenance operations, 3) accidental release of $\mathrm{H}_{2} \mathrm{~S}$ (especially in mixtures of septic wastes), 4) accidental effluent discharge, 5) overflowing sewage systems or storm-water control due to exceptional downpours, presence of dangerous products in the raw material used to produce biogas, overflow, freezing of valves and high pressure inside the digester. All these risks are enhanced by different features concerning biogas plants, such as:

- the diversity of employed processes (from wastewater treatment to solid waste treatment, or biomass valorisation by farmers) together with the absence of reference documents clearly defining, at international level, the state of the art regarding safety;

- the lack of clear regulations and standards regarding the safety of biogas production and use, and the lack of enforcement of the existing occupational health and safety regulation (including ATEX);

- the lack of organised communication channels to share the experiences (near-misses, accidents, and also positive experiences) between the industry players, but also with the usual stakeholders such as authorities, insurance companies and the public.

In order to improve both the knowledge and the global safety of biogas plants, this work reports a simple but accurate risk assessment that has been carried out on a case study biogas plant (the real plant is located in Italy). In particular, a fault tree analysis has been applied in order to quantify the probability of 
occurrence of the top event "fire in the digester" which is one of the main causes of accident in this plants typology. Results arising from this study have shown that the overall risk (considering one year of mission time) is under $10^{-8} \mathrm{y}^{-1}$. This value can be considered acceptable since, generally, near these plants, the number of inhabitants do not exceed 100 persons (in most cases, 10 persons is the maximum number).

\section{Description of the plant}

The quantitative risk assessment (QRA) reported in this case study concerns the design phase of a biogas plant sited in the north-east of Italy. In accordance with the desired configuration, the plant will produce biogas through anaerobic digestion of white meat cattle slurry (about 1,600 animals), as well as manure produced by chickens raised on broilers with straw (about 150,000 units). The biogas produced will be then processed in an internal combustion engine for the production of electricity. Part of the energy produced during the combustion process will be also recovered through the heating of water used within the company and for the production of warm milk for veal calves and for the maintenance of mesophilic conditions (about $38-39^{\circ} \mathrm{C}$ ) within the digester. It is also estimated a daily production of biogas of around 1,150 $\mathrm{Nm}^{3} /$ day (with a methane $\mathrm{v} / \mathrm{v}$ percentage of approximately $50 \%$ ).

The plant object of the present study is constituted of several parts, listed below:

a) Sump for the collection of the slurry coming from manure of calves;

b) Pre-tank, equipped with a trap door, intended for the manual daily loading of poultry manure;

c) Pumping room (located in a container);

d) Emergency flare;

e) One digester, insulated and heated, with two immersion stirrer, covered with a double plastic sheeting hood;

f) Ducts for the biogas transport to the co-generator;

g) Water storage tank used by the fire-fighting network;

h) One $100 \mathrm{kWe}$ co-generator;

i) Tank for the storage of the digestate;

j) Solid-liquid separator;

k) Accumulation stall for the separated solid;

1) Storage tank for the clarified fraction of the digestate;

m) Nitrification and denitrification tanks for the clarified fraction of the digestate.

All these constitutive parts of the plant have been reported in Figure 1, which shows the actual planimetry of the plant. 


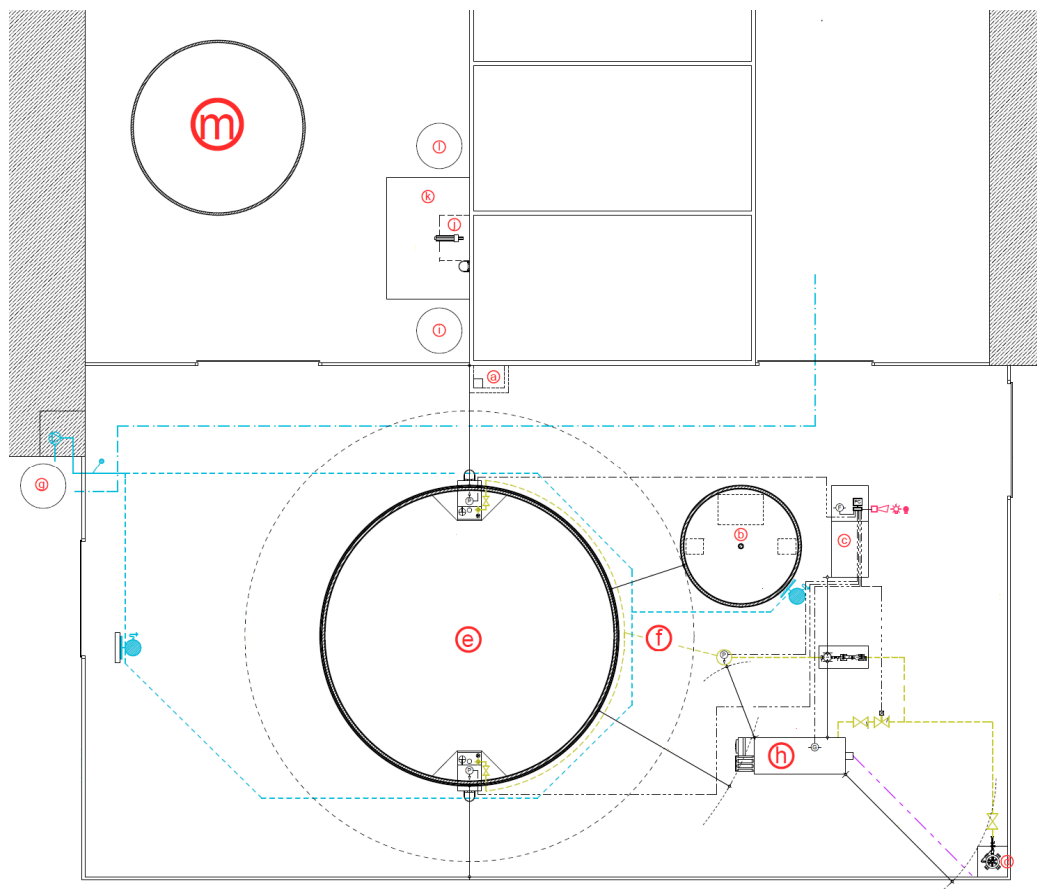

Figure 1: Planimetry of the case study biogas plant.

\section{Risk assessment in industrial plants}

\subsection{General methods for risk assessment}

Referring to technology, risk analysis is a scientifically structured discipline, that is a set of methodologies for the determination of the so-called "risk function", sufficiently developed and systematised at conceptual level. The ultimate goal is always to take the lead in a decision making process [13].

The estimate of the risk arising from the exercise of a particular industrial activity is generally performed with a methodology that, starting from statistical data derived from the history of accidents actually occurred in plants similar to the one under study, will complete a series of specific analyses, related to a particular facility and the site where it is installed, in order to obtain a sufficiently accurate estimate of the risk. In the case of mature and widespread technologies, the statistics of accidents can be so broad as to allow the direct realistic estimate of the risk or, at least, the probability of occurrence of conceivable accidents. The determination of the consequences depends very much on the site, for what concerns the aspects of meteorology and hydrology, population distribution, etc.; therefore, it is generally necessary an adaptation of the statistical data to the particular case study. If you do not have a statistic 
sufficiently complete to be referred to, an analytical methodology to perform a risk assessment on a theoretical basis can be employed.

The risk in the performance of an industrial activity results from the use of potentially hazardous materials. The starting point of a risk analysis is always the identification of hazardous substances and the process that they undergo in the system under study. This procedure is usually referred to as hazard identification.

The protection system (more or less sophisticated) of the plant comes into play at this point, to prevent or, at least, limit the possible effects of an accidental event. Therefore, the adverse event occurs only if you have, at the same time, the failure of the process system and the failure of the protections that the system provided to confine the incident.

Considering the physical and chemical phenomena involved in an accident you are able to evaluate their effect on individuals, economic systems, social systems, etc., through:

a) an identification of the events that contribute to the risk;

b) an estimate of the probability of occurrence of such events and their consequences;

c) a determination of the risk function and its use for decision making.

To develop such an analysis, a thorough knowledge of the system and the industrial process implemented in it has to be acquired for the search of those failures which may constitute the source of accidents (initiating events).

The risk analyst must then develop a model of the system that allows the identification of the possible states of the latter arising from each initiating event. To estimate the probability of occurrence of each state of the system, we can make use of appropriate techniques such as fault tree analysis.

The next step is the determination of all accidental scenarios associated with each degraded state of the system (sequence of events), possibly "filtered" by the effect of the available protection systems. At this point, in order to identify the consequences for each category of accidents, it is necessary to develop an environmental impact model that describes the magnitude of the consequences of each scenario. In this phase, the possible implementation of an external emergency plan can take a decisive role for the mitigation of the consequences of the accident. Finally, after determining the probability of occurrence of each accidental event, the integration of all results, (defined as an estimate of the magnitude and frequency of occurrence) on the entire spectrum of the categories of accidental scenarios, allows for the determination of the function associated with the risk linked to the activity in question. Normally, on the basis of this risk function, decision-makers (political or technical, depending on the stage at which the study is actually applied) take the appropriate decisions.

\subsection{Fault tree analysis}

Fault tree analysis is a technique suitable for both determining the credible modes of occurrence of an undesired event (called, top event), caused by a complex concatenation of other events (qualitative analysis), and estimating the frequency of occurrence of undesired event on the basis of frequency of 
occurrence of the events that cause it (quantitative analysis [14]). It is a deductive methodology particularly suitable for the analysis of complex systems whose development can be easily decomposed into a succession of more simple events, and therefore it is well suited to the analysis of industrial installations.

Once all the systems (and their parts) have been identified, it is necessary to continue the analysis of the chain of systems, subsystems, equipment, etc., up to the failure of the individual components for which we are in possession of sufficient information on the probabilities of failure to be used in the evaluation.

These are combined through logical operations (and/or), also called logic gates, going from bottom to up, until you get to determine the probability of the top event. The fault tree analysis allows you to treat the contribution to risk arising from human error, as well as other causes of failure common to several subsystems. Clearly, it is possible to use fault trees also for qualitative analysis. In this case, there is the advantage of highlighting the main causes of an accident (e.g., whether failures of equipment or human error) so that you can focus on preventive measures to reduce the probability of the accident itself.

The representation of a fault tree uses some symbols with standardised meanings; the main graphic symbols are summarised in Table 1.

Table 1: Graphic symbols for fault tree analysis.

\begin{tabular}{|l|l|}
\hline Graphic symbol & $\begin{array}{l}\text { Meaning } \\
\text { not further investigated; if you want to perform a } \\
\text { quantitative analysis to estimate the frequency of occurrence } \\
\text { of the top event you need to know the frequency of } \\
\text { occurrence of these primary events, for example, estimating } \\
\text { it through a historical analysis. }\end{array}$ \\
\hline $\begin{array}{l}\text { Intermediate events: these are events that occur before or } \\
\text { after another event and represent the cause of the next event; } \\
\text { they are connected to the events preceding or following } \\
\text { them by gates. }\end{array}$ \\
\hline $\begin{array}{l}\text { OR-gate: so that the output of the gate takes place, it is } \\
\text { sufficient that one of the inputs to the gate itself (which may } \\
\text { be any number greater than 1) occurs. }\end{array}$ \\
$\begin{array}{l}\text { AND-gate: } \text { so that the output of the gate happens, it is } \\
\text { necessary that all the inputs to the gate itself (which may be } \\
\text { any number greater than 1) occur. }\end{array}$ \\
\hline
\end{tabular}

\subsubsection{Quantitative risk analysis}

The quantification of a fault tree has essentially the aim of quantifying the reliability $R(t)$ of a system, that is the probability that, in correspondence of an allotted time interval (also called mission time, $t$ ), a system performs properly the function for which it was built. From this definition it is clear that the reliability of a system is inversely proportional to the mission time: the longer the time of the mission, the smaller results to be the reliability of the system (or it is more likely that the system fails). 
It is important to note that the quantification of the fault tree is an operation valid for orders of magnitude; in other words, the results cannot be compared on the basis of small differences. For example, 1.5 and 4.1 are essentially the same number while 3.5 to 0.12 are two numbers significantly different. It follows that no unnecessarily high accuracy is required in the input data (i.e., in the estimate of the probabilities of occurrence of the primary events).

\subsubsection{Primary events quantification}

For a system whose modes of failure can be represented in a fault tree, the information contained in $R(t)$ are usually summed in the following functions: the unavailability $q(t)$, which is the probability that the system is not able to perform its function (because it is broken) at time $t$, and the frequency of occurrence $W(t)$, which is the number of times that the system is not expected to be able to perform its function in its mission time.

To quantify a fault tree is first necessary to calculate these quantities for all primary events that have been identified in the construction of the fault tree itself.

If the component involved in the primary event is not repairable, the component is no longer able to perform its function at time $t$ if it is spoiled before the same time $t$; its unavailability therefore coincides with its unreliability, namely:

$$
q(t)=\lambda t
$$

where $\lambda$ is the failure rate, that is, the frequency with which a system fails (or the fraction of the components that fail per unit of time, $\left.\mathrm{y}^{-1}\right)$ and $t$ is time, $\mathrm{y}$.

If the component is repairable, its unavailability no longer coincides with its unreliability, since, even if the component had spoiled before time $t$, may still perform its function at time $t$ in the case where it has been repaired. In this case, it is possible to demonstrate that the unavailability reaches an asymptotic value equal to:

$$
q(t)=\frac{\lambda T_{D}}{1+\lambda T_{D}} \approx \lambda T_{D}=\frac{\lambda}{\mu}
$$

where $T_{D}$ is the mean repair time, that is the time necessary to repair the component, and $\mu=1 / T_{D}$ is the repair rate, that is, the frequency with which a component can be repaired. For practical purposes, the unavailability can be approximated by the probability that the component has failed in the time interval $T_{D}$ previous than the instant of time considered (therefore, resulting failure at time $t$ ). 


\subsubsection{Minimal cut sets and top event quantification}

A minimal cut set (MCS) is the minimum combination of primary events, which is necessary and sufficient to ensure the occurrence of the top event; in equivalent terms, the top event occurs if all the events in a MCS occur simultaneously. Then, the unavailability of a MCS is the probability that, at time $t$, all the system components are not able to perform their function; therefore, this probability coincides with the probability of occurrence of the top event due to the considered MCS. Since the individual events involved in a MCS are all independent, the overall probability that all events occur simultaneously is given by the following relation:

$$
q(t)=\prod_{i=1}^{n} q_{i}(t)
$$

where $n$ is the order of the MCS (the number of events that involves the MCS) and $q_{i}(t)$ is the unavailability of each component of the MCS.

The frequency of occurrence of the MCS, which coincides with the frequency of occurrence of the top event in the mission time $(T)$ because of the MCS considered, is then calculated as:

$$
W(t)=\int_{o}^{T}\left[\sum_{i=1}^{n}\left(\left(\prod_{\substack{j=1 \\ j \neq i}}^{n} q_{j}(t)\right) \lambda_{i}\right)\right] d t
$$

A top event can occur if anyone of the MCS that can cause it occurs. The likelihood of the top event in a given interval of time can thus be calculated as the union (logical OR) of the probability of occurrence of each MCS that can cause the top event itself.

\section{Case study risk assessment}

In accordance with the purposes of the present work, we proceeded with the drafting of the fault tree concerning the top event "occurrence of fire within a gasometer for the production and containment of biogas".

For what concerns the layout of the plant and its functioning, reference has been made to the planimetry shown in Figure 1.

Figure 2 shows the graphical representation of one of the sub-tree (E10) concerning the top event cited above. Observing the tree, it can be derived clearly the chain of events (defined as failure) such as to generate the occurrence of a fire within the gasometric dome due to that specific sequence of failures. 


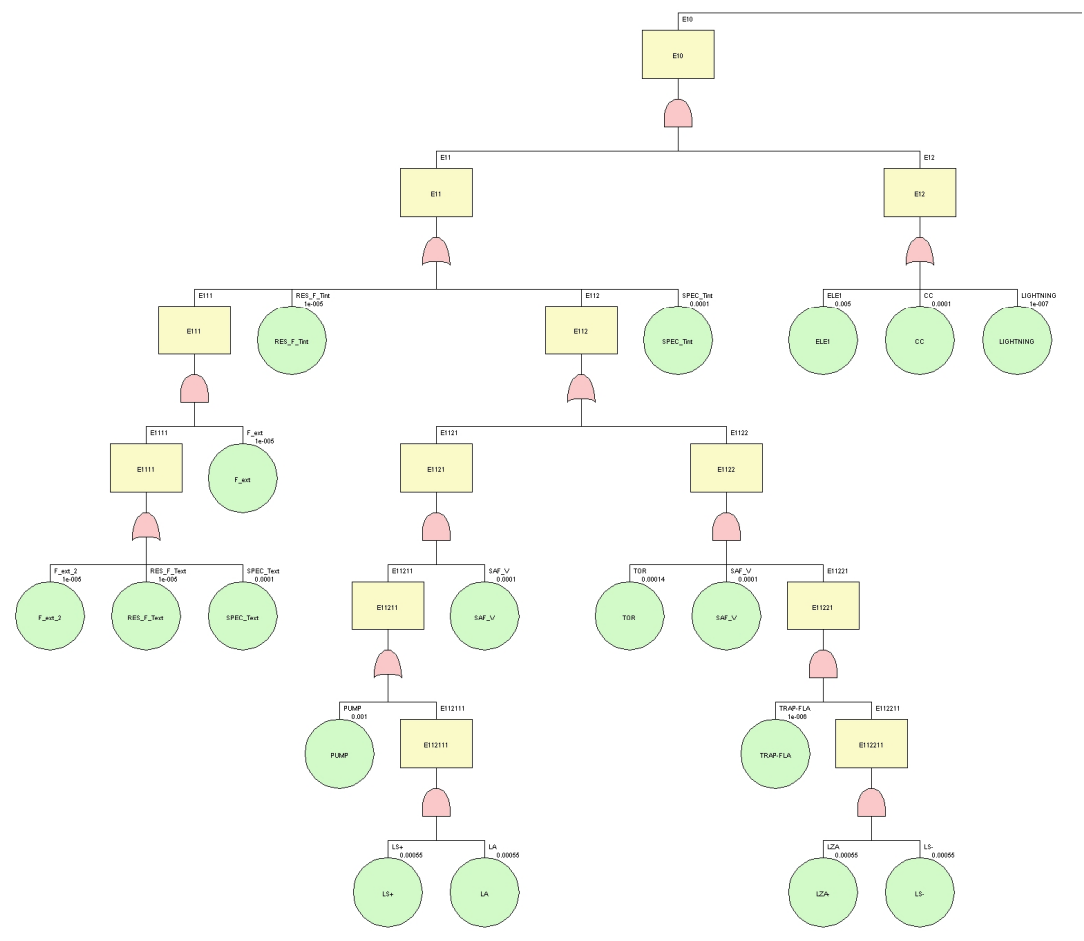

Figure 2: Sub-tree E10 for the top event: "fire in the digester".

In particular, the top event takes place in the case where at least one of the following final intermediate events occurs:

$>$ E10: formation of a flammable mixture within the gasometric dome because of accidental mixing between biogas and air and the simultaneous presence of an ignition source (spark, flame welding, etc.);

$>$ E20: explosion of the gasometric dome due to the propagation of a fire (not readily extinguished) in the adjacent stables;

$>$ E30: formation of a flammable mixture within the gasometric dome due to a malfunction in the desulfurization unit (which blows air inside the gasometric dome from the outside);

$>$ E40: flashback from the cogeneration plant.

In order to perform the quantitative calculation of the frequency of occurrence of the top event, we have expressed all the causes originating the intermediate events (final or not) until you get to the primary events (rupture of simple components such as valves, level controllers, etc.), for which it has been possible to estimate the relative unavailability and frequencies of occurrence in accordance with appropriate databases (relative to similar systems). 
It is important to emphasize that, within the scheme of the fault tree, the presence of all the protective devices useful in order to avoid a fire or an explosion of the gasometric dome has been considered.

Performing the analysis of all MCS, it is possible to observe that minimal cut sets of order higher than 5 do not exist and, moreover, there are no MCS of order 1 (this is extremely positive because there are no events that, alone, can cause the top event). Among the MCS of order 2, we have the combinations of events in which, due to exceeding of the fatigue strength of the inner sheeting hood (RES_F_Tint) or its production out of specification (inner sheeting defective, SPEC_Tint), there is the formation of a flammable mixture inside the gasometric dome that can be triggered by a short circuit (CC), improper maintenance of the electrical service (ELE1) or lightning strikes in the vicinity of the dome (LIGHTNING). Among the MCS of order 3 (16 different), there are events in which the formation of a flammable mixture within the gasometer is given by the failure of components such as the pump of the water trap used for the collection of the condensate (PUMP), the safety valve of the dome (SAF_V), the concentration meters of hydrogen sulphide (MIS_H2S) and oxygen (MIS_OX), etc. while the trigger is through the classic CC, ELE1 and LIGHTNING events. In only one case a MCS of order $3\left(n^{\circ} 16\right)$ does not involve an ignition source of the types previously cited: it is the accidental scenario in which a flashback from the co-generator occurs because of the simultaneous breakage of both the flame trap and the two emergency low level switches of the water trap.

Of particular interest is the unique MCS of order 5: it expresses the combination of events that lead to the top event due to the development of a fire (not promptly extinguished) in the stables adjacent to the gasometric dome and its subsequent propagation to the dome itself. In order to compute the probability of occurrence of such a MCS is, however, required the calculation of the probability that the wind (WIND) blows towards south during the development of the fire itself. This estimation cannot be obtained from any database as it is closely related to the location of the site in which the plant is constructed. Therefore, to assess the mean wind direction during of year of mission time, meteorological data from two different weather stations (located near the plant site) has been collected.

Analysing such data, it can be reasonably assumed that the wind blows at the southern quadrant with a probability of about $50 \%$ during the year.

As regards the retrieval of all failure rates and unavailability, Dossier Ambiente manuals [15] have been taken as a reference. Moreover, it has been considered a repair rate equal to 1 day $^{-1}$.

Table 2 shows, in a schematic way, all the data necessary for the quantification of the fault tree. Referring to the database shown in Table 2, it can be possible to proceed with the calculation of the probability of occurrence of the top event. 
Table 2: Database for failure rates, repair rates and unavailability.

\begin{tabular}{|c|c|c|c|}
\hline Primary event code and description & $\begin{array}{c}\text { Failure } \\
\text { rate } \\
{\left[\mathbf{y}^{-1}\right]}\end{array}$ & $\begin{array}{c}\text { Repair } \\
\text { rate } \\
{\left[\mathbf{y}^{-1}\right]}\end{array}$ & $\begin{array}{c}\text { Unavailability } \\
{[-]}\end{array}$ \\
\hline CC: short circuit & - & - & $1 \cdot 10^{-4}$ \\
\hline ELE1: electric sparks due to improper maintenance & - & - & $5 \cdot 10^{-3}$ \\
\hline FAIL-ANT: stables sprinklers failure & - & - & $1 \cdot 10^{-2}$ \\
\hline LIGHTNING: lightning in the vicinity of the dome & - & - & $1 \cdot 10^{-7}$ \\
\hline F_ext: external factors on internal sheeting & - & - & $1 \cdot 10^{-5}$ \\
\hline F_ext_2: external factors on external sheeting & - & - & $1 \cdot 10^{-5}$ \\
\hline FIRE_STA: fire in the stables & - & - & $1 \cdot 10^{-2}$ \\
\hline LA: failure of the low level alarm & $2 \cdot 10^{-1}$ & 365 & $5.5 \cdot 10^{-4}$ \\
\hline LS+: failure of the high level switch & $2 \cdot 10^{-1}$ & 365 & $5.5 \cdot 10^{-4}$ \\
\hline LS-: failure of the low level switch & $2 \cdot 10^{-1}$ & 365 & $5.5 \cdot 10^{-4}$ \\
\hline LZA: failure of the ultimate low level alarm & $2 \cdot 10^{-1}$ & 365 & $5.5 \cdot 10^{-4}$ \\
\hline MIS_H2S: failure of the H2S controller & $5 \cdot 10^{-3}$ & 365 & $\sim 1 \cdot 10^{-5}$ \\
\hline MIS_OX: failure of the O ${ }_{2}$ controller & $5 \cdot 10^{-3}$ & 365 & $\sim 1 \cdot 10^{-5}$ \\
\hline PUMP: failure of water trap pump & $4 \cdot 10^{-1}$ & 365 & $1 \cdot 10^{-3}$ \\
\hline RES_F_Text: overcoming of the external sheeting & - & - & $1 \cdot 10^{-5}$ \\
fatigue resistance & & & $1 \cdot 10^{-5}$ \\
\hline RES_F_Tint: overcoming of the internal sheeting & - & - & $1 \cdot 10^{-4}$ \\
\hline fatigue resistance & - & - & $1 \cdot 10^{-4}$ \\
\hline SAF_V: failure of the dome safety valve & - & - & $1 \cdot 10^{-4}$ \\
\hline SPEC_Text: external plastic sheeting out of specific & - & - & $1 \cdot 10^{-4}$ \\
\hline SPEC_Tint: internal plastic sheeting out of specific & - & - & $5 \cdot 10^{-1}$ \\
\hline TOR: failure of the flare valve & $5 \cdot 10^{-2}$ & 365 & \\
\hline TRAP-FLA: failure of the flame trap & - & - & - \\
\hline WIND: wind direction towards south & - & & \\
\hline
\end{tabular}

\section{Results and conclusions}

Analysing the fault tree generated for the incidental event "fire in a gasometer", it has been showed that the probability of occurrence of the top event (considered a mission time equal to 1 year) is of the order of $10^{-8}$. This value lies within the zone of acceptability of the risk (considered as individual risk), as the limit value of unacceptability is equal to $10^{-6}$ (given in accordance with the recommendations of Italian fire-fighters). It can be also noted that the presence of ignition sources such as short circuit or incorrect maintenance of the electrical service weigh significantly within the MCS in which they are involved, respectively $17 \%$ and $83 \%$, for the purposes of the occurrence of the top event.

Other events that are of considerable importance are the resistance to fatigue and the possibility of abnormalities in the inner sheeting hood (about 50\%), followed by failure of concentration controllers of $\mathrm{H}_{2} \mathrm{~S}$ and oxygen in the dome $(1.23 \%)$ and breakages of the pump in the water trap and the safety valve of the dome $(0.49 \%)$. 


\section{References}

[1] Salvi, O., Delsinne, S., Evanno, S., Biogas - A European Perspective on Safety and Regulation. Journal of Risk Analysis and Crisis Response, 1(1), 1-20, 2011.

[2] Divya, D., Gopinath, L.R., Merlin Christy, P., A review on current aspects and diverse prospects for enhancing biogas production in sustainable means. Renewable and Sustainable Energy Reviews, 42, 690-699, 2014.

[3] Boontian, N., Optimization of the anaerobic digestion of biomass: A review. Romanian Review Precision Mechanics, Optics and Mechatronics, 43, 48-54, 2013.

[4] Kasiri, S., Mah, F., Zhang, C., Haveroen, M., Ellsworth, S., Ulrich, A., Anaerobic processes, Water Environment Research, 84(10), 1217-1285, 2012.

[5] Rada, E.C., Ragazzi, M., Ionescu, G., Merler, G., Moedinger, F., Raboni, M., Torretta, V., Municipal solid waste treatment by integrated solutions: energy and environmental balances. Energy Procedia, 50, 1037-1044, 2014.

[6] Torretta, V., Ionescu, G., Raboni, M., Merler, G., The mass and energy balance of an integrated solution for municipal solid waste treatment. WIT Transactions on Ecology and the Environment, 180, 151-161, 2014.

[7] Rada, E.C., Ragazzi, M., Torretta, V., Laboratory-scale anaerobic sequencing batch reactor for treatment of stillage from fruit distillation. Water Science \& Technology, 67(5), 1068-1074, 2013.

[8] Callegari, A., Torretta, V., Capodaglio, A.G., Preliminary trial application of biological desulfonation in anaerobic digestors from pig farms. Environmental Engineering and Management, 12(4), 815-819, 2013.

[9] Martinez, S., Torretta, V., Minguela, J., Siñeriz, F., Raboni, M., Copelli, S., Rada, E.C., Ragazzi, M., Treatment of slaughterhouse wastewaters using anaerobic filters. Environmental Technology, 35(3), 322-332, 2014.

[10] Nardin F., Mazzatto, F., Mapping of biomass fluxes: a method for optimizing biogas-refinery of livestock effluents, Sustainability, 6(9), 5920-5940, 2014.

[11] Trulli, E., Torretta, V., Influence of feeding mixture composition in batch anaerobic co-digestion of stabilized municipal sludge and waste from dairy farms. Environmental Technology, Doi: 10.1080/ 09593330.2014.994045. In press.

[12] Observ'ER. The State of Renewable Energies in Europe. $\mathrm{http} / / / \mathrm{www}$.energies-renouvelables.org/

[13] Di Mauro, C., Bouchon, S., Torretta, V., Industrial Risk in the Lombardy Region (Italy): what People perceive and what are the gaps to improve the Risk Communication and the Participatory Processes. Chemical Engineering Transactions, 26, 297-302, 2012.

[14] Vaseley, W.E., Goldberg, F.F., Roberts, N.H., Haasl, D.F., Fault Tree Handbook, U.S. Nuclear Regulatory Commission Washington D.C., 1981.

[15] Dossier Ambiente, http://www.amblav.it/dossier.aspx 